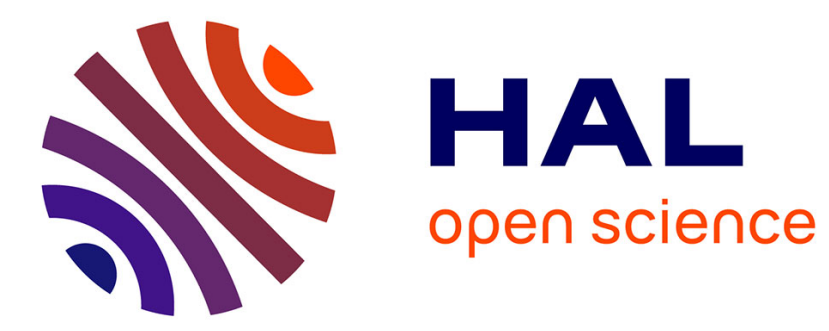

\title{
A Harmonic Mean Inequality Concerning the Generalized Exponential Integral Function
}

\author{
Kwara Nantomah
}

\section{To cite this version:}

Kwara Nantomah. A Harmonic Mean Inequality Concerning the Generalized Exponential Integral Function. 2021. hal-03224564

\author{
HAL Id: hal-03224564 \\ https://hal.science/hal-03224564 \\ Preprint submitted on 11 May 2021
}

HAL is a multi-disciplinary open access archive for the deposit and dissemination of scientific research documents, whether they are published or not. The documents may come from teaching and research institutions in France or abroad, or from public or private research centers.
L'archive ouverte pluridisciplinaire $\mathbf{H A L}$, est destinée au dépôt et à la diffusion de documents scientifiques de niveau recherche, publiés ou non, émanant des établissements d'enseignement et de recherche français ou étrangers, des laboratoires publics ou privés. 


\title{
A HARMONIC MEAN INEQUALITY CONCERNING THE GENERALIZED EXPONENTIAL INTEGRAL FUNCTION
}

\author{
KWARA NANTOMAH
}

\begin{abstract}
In this paper, we prove that for $s \in(0, \infty)$, the harmonic mean of $E_{k}(s)$ and $E_{k}(1 / s)$ is always less than or equal to $\Gamma(1-k, 1)$. Where $E_{k}(s)$ is the generalized exponential integral function, $\Gamma(u, s)$ is the upper incomplete gamma function and $k \in \mathbb{N}$.
\end{abstract}

\section{INTRODUCTION}

Special functions play a pivotal role in both pure and applied mathematics. In particular, they are frequently encountered in mathematical analysis, mathematical physics, probability and statistics, and engineeering.

The classical exponential integral which is one of the most celebrated special functions is defined for $s>0$ as [1, p. 228]

$$
\begin{aligned}
E(s) & =\int_{s}^{\infty} \frac{e^{-t}}{t} d t \\
& =\int_{1}^{\infty} \frac{e^{-s t}}{t} d t \\
& =\Gamma(0, s)
\end{aligned}
$$

where $\Gamma(u, s)$ is the upper incomplete gamma function defined as

$$
\Gamma(u, s)=\int_{s}^{\infty} t^{u-1} e^{-t} d t .
$$

It may also be defined as follows

$$
\begin{aligned}
E(s) & =-\gamma-\ln s+\sum_{r=1}^{\infty} \frac{(-1)^{r+1} s^{r}}{r ! r} \\
& =-\ln s+e^{-s} \sum_{r=0}^{\infty} \frac{s^{r}}{r !} \psi(r+1)
\end{aligned}
$$

where $\gamma$ is the EulerMascheroni constant and $\psi($.$) is the digamma function.$

2010 Mathematics Subject Classification. 26D07, 26D20, 33Bxx.

Key words and phrases. Harmonic mean inequality, exponential integral function, incomplete gamma function. 
The generalized exponential integral function is defined as [7]

$$
\begin{aligned}
E_{k}(s) & =s^{k-1} \int_{s}^{\infty} \frac{e^{-t}}{t^{k}} d t \\
& =\int_{1}^{\infty} \frac{e^{-s t}}{t^{k}} d t \\
& =s^{k-1} \Gamma(1-k, s)
\end{aligned}
$$

where $k \in \mathbb{N}$ is the order of the integral and $E_{1}(s)=E(s)$. It is also known in some text as the Theis well function [2]. This special function has useful applications in astrophysics, neutron physics, quantum chemistry, hydrology and other applied sciences. As a result of its practical importance, it has been investigated in different directions. For example, see [2], [3], [4], [6], [8], [9], [10], [12] and the references therein.

In a recent work [5], it was established that for $s \in(0, \infty)$, the harmonic mean of $E(s)$ and $E(1 / s)$ is always less than or equal to $\Gamma(0,1)=0.21938393 \ldots$. In this work, the goal is to extend this result to the generalized function $E_{k}(s)$. We present our findings in the following sections.

\section{Results}

Lemma 2.1. The function $\frac{s E_{k}^{\prime}(s)}{E_{k}^{2}(s)}$ is strictly decreasing on $(0, \infty)$.

Proof. By identity (2) we obtain

$$
E_{k}^{\prime}(s)=\frac{(k-1) E_{k}(s)-e^{-s}}{s}
$$

and since $E_{k}(s)$ is decreasing, then

$$
(k-1) E_{k}(s)<e^{-s} .
$$

Now let

$$
\left.T(s)=\frac{s E_{k}^{\prime}(s)}{E_{k}^{2}(s)}\right)=\frac{(k-1) E_{k}(s)-e^{-s}}{E_{k}^{2}(s)}
$$

for $s \in(0, \infty)$. Then by differentiating and using (1) and (3), we obtain

$$
\begin{aligned}
E_{k}^{3}(s) T^{\prime}(s) & =-(k-1) E_{k}(s) E_{k}^{\prime}(s)+e^{-s} E_{k}(s)+2 e^{-s} E_{k}^{\prime}(s) \\
& <-e^{-s} E_{k}^{\prime}(s)+e^{-s} E_{k}(s)+2 e^{-s} E_{k}^{\prime}(s) \\
& =e^{-s}\left[E_{k}(s)+E_{k}^{\prime}(s)\right] \\
& =e^{-s} \int_{1}^{\infty}\left[\frac{1-t}{t^{k}}\right] e^{-s t} d t \\
& <0 .
\end{aligned}
$$

Hence, $T^{\prime}(s)<0$ and this completes the proof of the lemma.

Theorem 2.2. For $s \in(0, \infty)$ and $k \in \mathbb{N}$, the inequality

$$
\frac{2 E_{k}(s) E_{k}(1 / s)}{E_{k}(s)+E_{k}(1 / s)} \leq \Gamma(1-k, 1)
$$

is satisfied. Equality holds when $s=1$. 
Proof. The case for $s=1$ is apparent. So let $Q(s)=\frac{2 E_{k}(s) E_{k}(1 / s)}{E_{k}(s)+E_{k}(1 / s)}$ and $\chi(s)=$ $\ln Q(s)$ for $s \in(0,1) \cup(1, \infty)$. Then direct computation, we obtain

$$
\chi^{\prime}(s)=\frac{E_{k}^{\prime}(s)}{E_{k}(s)}-\frac{1}{s^{2}} \frac{E_{k}^{\prime}(1 / s)}{E_{k}(1 / s)}-\frac{E_{k}^{\prime}(s)-\frac{1}{s^{2}} E_{k}^{\prime}(1 / s)}{E_{k}(s)+E_{k}(1 / s)}
$$

and this implies that

$$
s\left[E_{k}(s)+E_{k}(1 / s)\right] \chi^{\prime}(s)=s \frac{E_{k}^{\prime}(s)}{E_{k}(s)} E_{k}(1 / s)-\frac{1}{s} \frac{E_{k}^{\prime}(1 / s)}{E_{k}(1 / s)} E_{k}(s) .
$$

Further manipulation reveals that

$$
\begin{aligned}
s\left[\frac{1}{E_{k}(s)}+\frac{1}{E_{k}(1 / s)}\right] \chi^{\prime}(s) & =s \frac{E_{k}^{\prime}(s)}{E_{k}(s)}-\frac{1}{s} \frac{E_{k}^{\prime}(1 / s)}{E_{k}(1 / s)} \\
& =A(s) .
\end{aligned}
$$

As a consequence of Lemma 2.1, we conclude that $A(s)>0$ if $s \in(0,1)$ and $A(s)<0$ if $s \in(1, \infty)$. This implies that, $\chi^{\prime}(z)>0$ if $s \in(0,1)$ and $\chi^{\prime}(s)<0$ if $s \in(1, \infty)$. Therefore, $Q(s)$ is increasing on $(0,1)$ and decreasing on $(1, \infty)$. For both cases, we arrive at

$$
Q(s)<\lim _{s \rightarrow 1} Q(s)=E_{k}(1)=\Gamma(1-k, 1)
$$

and this concludes the proof of the theorem.

Figure 1 is a graphical illustration of the results of Theorem 2.2 for the special cases where $k=1, k=2, k=3, k=4$ and $k=5$.

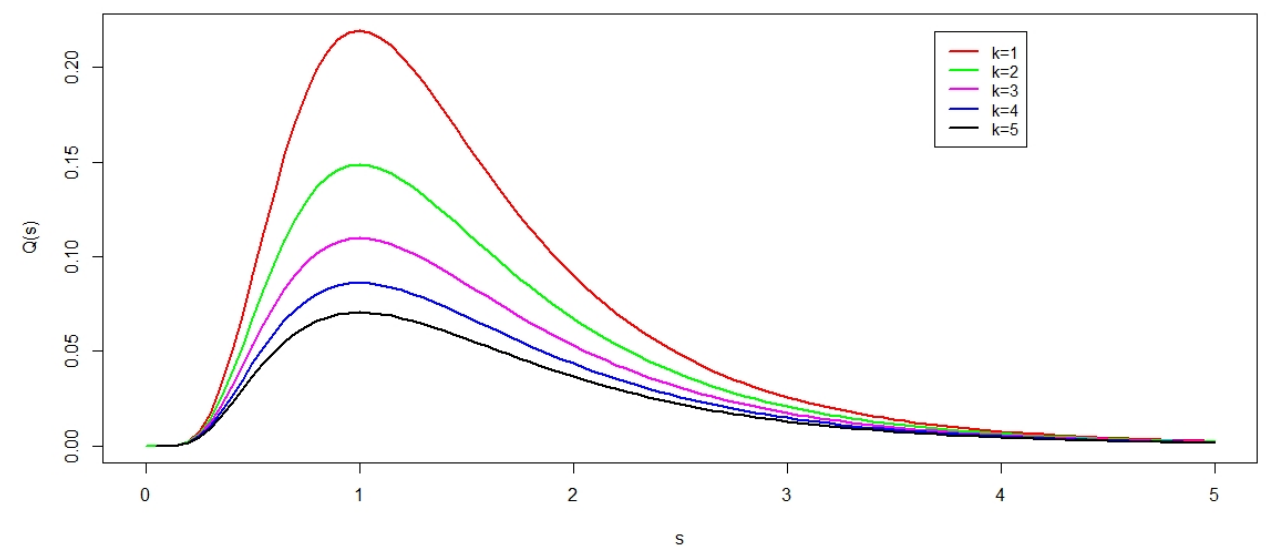

Figure 1. Plot of $Q(s)$ for some particular values of $k$. 


\section{Concluding Remarks}

Let $\mathcal{H}(u, v)=\frac{2 u v}{u+v}, \mathcal{A}(u, v)=\frac{u+v}{2}$ and $\mathcal{Q}(u, v)=\sqrt{\frac{u^{2}+v^{2}}{2}}$ respectively be the harmonic mean, arithmetic mean and root-square mean of $u$ and $v$. In this paper, we have proved that

$$
\mathcal{H}\left(E_{k}(s), E_{k}(1 / s)\right) \leq \Gamma(1-k, 1)
$$

where $s \in(0, \infty)$. This is equivalent to

$$
\mathcal{A}\left(\frac{1}{E_{k}(s)}, \frac{1}{E_{k}(1 / s)}\right) \geq \frac{1}{\Gamma(1-k, 1)} .
$$

Also, since $Q(u, v) \geq A(u, v)[11]$, then we have

$$
\mathcal{Q}\left(\frac{1}{E_{k}(s)}, \frac{1}{E_{k}(1 / s)}\right) \geq \frac{1}{\Gamma(1-k, 1)}
$$

which implies that

$$
\mathcal{H}\left(E_{k}^{2}(s), E_{k}^{2}(1 / s)\right) \leq \Gamma^{2}(1-k, 1)<\Gamma(1-k, 1) .
$$

For the particular case where $k=1$, inequality (5) reduces to the results of [5]. We anticipate that the results of this paper will inspire further studies on the generalized exponential integral function.

\section{REFERENCES}

[1] M. Abramowitz and I. A. Stegun, Handbook of Mathematical Functions with formulas, Graphic and Mathematical Tables, Dover Publications, Inc., New York, (1965).

[2] D. A. Barry, J-Y. Parlange and L. Li, Approximation for the exponential integral (Theis well function), J. Hydrol., 227(2000), 287-291.

[3] P. K. Bhandari and S. K. Bissu, On some inequalities involving Turan-type inequalities, Cogent Math., 3(1)(2016), Article: 1130678.

[4] C. Chiccoli, S. Lorenzutta and G. Maino, Recent Results for Generalized Exponential Integrals, Computers Math. Applic., 19(5)(1990), 21-29.

[5] K. Nantomah, A Harmonic Mean Inequality for the Exponential Integral Function, 2021. hal-03220402. Available online at: https://hal.archives-ouvertes.fr/hal-03220402

[6] K. Nantomah, F. Merovci and S. Nasiru, A Generalization of the Exponential Integral and Some Associated Inequalities, Honam Mathematical J., 39(1)(2017), 49-59.

[7] F. W. J. Olver, D. W. Lozier, R. F. Boisvert and C. W. Clark, (eds) NIST Handbook of Mathematical Functions, Cambridge University Press, London, 2010.

[8] A. Salem, A q-analogue of the exponential integral, Afr. Mat. 24(2013), 117-125.

[9] B. Sroysang, On the $n$-th Derivative of the Exponential Integral Functions, Communications in Mathematics and Applications, 4(2)(2013), 141-144.

[10] W. T. Sulaiman, Turan Inequalities for the Exponential Integral Functions, Commun. Optim. Theory, 1(1)(2012), 35-41.

[11] L. Vuksic, Seiffert means, asymptotic expansions and inequalities, Rad Hrvat. Akad. Znan. Umjet. Mat. Znan., 19(2015), 129-142.

[12] A. Yakubu, K. Nantomah and M. M. Iddrisu, A p-analogue of the exponential integral function and some properties, Adv. Inequal. Appl., 2020 (2020), Article ID 7.

Department of Mathematics, Faculty of Mathematical Sciences, C.K. Tedam University of Technology and Applied Sciences, P. O. Box 24, Navrongo, UpperEast Region, Ghana.

E-mail address: knantomah@cktutas.edu.gh 